\title{
Experiences of Australian and New Zealand New Nursing and Midwifery Graduates Looking for Employment
}

\author{
Anthony Tuckett $^{\mathrm{a}, \mathrm{b}} \mathrm{PhD}, \mathrm{MA}, \mathrm{BN}, \mathrm{RN}$
}

Program Lead: Master of Nursing Program

The University of Queensland, School of Nursing, Midwifery and Social Work

Level 3, Chamberlain Building

St Lucia Campus, St Lucia, 4072, Queensland, AUSTRALIA

Email: a.tuckett@uq.edu.au

${ }^{a}$ Affiliate Professor

The University of British Columbia, School of Nursing

Vancouver Campus

3026190 Agronomy Rd, Vancouver, BC, V6T 1Z3, Canada

John L. Oliffe ${ }^{\text {a }}$, PhD, M.Ed., RN

Professor,

The University of British Columbia, School of Nursing

3026190 Agronomy Rd, Vancouver, BC, V6T 1Z3,Canada

Email: john.oliffe@nursing.ubc.ca

Telephone: $604-822-7638$

${ }^{a}$ Honorary Professor,

The University of Queensland, School of Nursing and Midwifery

Herston Rd, Herston, QLD, 4006, Australia

\section{Authorship Statement}

The listed authors meet the criteria for authorship and agree with the content of the manuscript.

\section{Disclosure Statement}

The authors declare no conflict of interest.

This is the author manuscript accepted for publication and has undergone full peer review but has not been through the copyediting, typesetting, pagination and proofreading process, which may lead to differences between this version and the Version of Record. Please cite this article as doi: $10.1111 / \mathrm{ijn} .12484$

This article is protected by copyright. All rights reserved. 


\section{ABSTRACT}

Aim: The aim of this research is to describe the experiences of Australian and New Zealand nursing and midwifery students looking for employment after graduation.

Methods: This qualitative study draws from 2008, 2009 and 2010 responses provided by 197 recently graduated Australian and New Zealand nurses and midwives to, Describe your experiences gaining employment as a nurse or midwife after graduation.

Results: Two themes were inductively derived, Taking what you can get and I had a job lined up. Within the taking what you can get theme respondents efforts to gain employment as a nurse or midwife after graduation were challenged by limited choices round the type of clinical practice available and/or job insecurity. In contrast for respondents in the I had a job lined up theme, employment after graduation was linked to job offers during student's clinical placements and/or hospitals where they completed their final practicum.

Conclusion: Understanding and better facilitating the transition of new nurse/midwife graduates to healthcare institutions is vitally important to sustaining the nursing workforce.

Keywords: new nursing graduates, new midwife graduates, nurse graduate employment, Australia, New Zealand

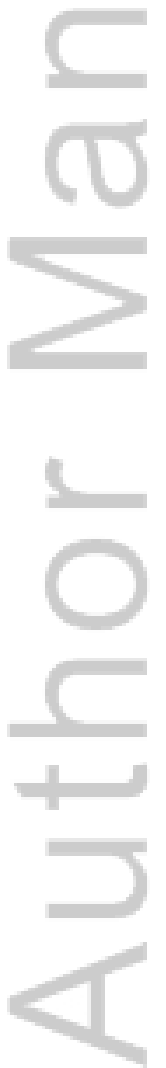

This article is protected by copyright. All rights reserved. 


\section{Summary Statement}

What is already known about the topic?

- Transitions for recent graduate nurse/midwifery students to registered nurse/midwife jobs are diverse and often challenging.

What this paper adds

- New Australian and New Zealand nursing and midwifery graduates typically travel one of two paths predetermined by their clinical experiences and networking as student nurses.

The implications of this paper for policy/practice/research/education

- Offers educators, policy makers and administrators insights toward supporting the transition from recent graduate nurse/midwifery student to registered nurse/midwife.

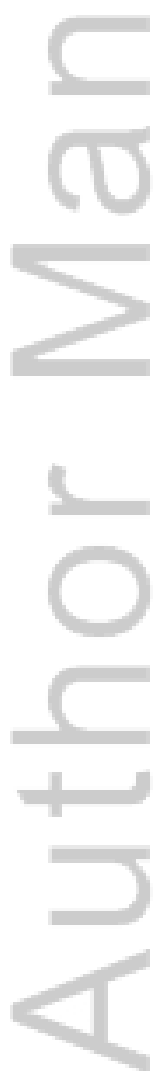

This article is protected by copyright. All rights reserved. 


\section{INTRODUCTION}

There is an array of reasons for understanding the experiences of newly graduated nursing and midwifery students. For example, the transition stage(s) for new graduates are diverse but reports suggest it can be 'stressful, frustrating, discouraging and disillusioning ${ }^{,(1,2)}$ and poorly understood. Work by Hayman and colleagues ${ }^{(3)}$ revealed new graduates face a lack of support, unrealistic organisational demands, a lack of confidence and feelings of unpreparedness. Others concur, noting the need for support ${ }^{(4,5)}$; being fearful and overwhelmed $^{(4)}$ or overworked ${ }^{(5)}$. In addition, concerns about an aging workforce ${ }^{(6)}$ and the supply of nurses and midwives ${ }^{(6)}$ highlights the need for new graduates to sustain clinical practice environments ${ }^{(7,8)}$. Educators, policy makers and administrators must therefore continue to seek viable solutions to improve the transition experiences of graduate nurses and midwives ${ }^{(2,4)}$.

Diverse new graduate nursing programs referred to as an 'internship' ${ }^{(9)}$; mentorship strategies ${ }^{(10)}$; the clinical focus program (CFP) ${ }^{(11)}$; the transition to speciality practice program (TSPP) ${ }^{(12)}$; a 12 month supported entry program (Career Development Year-CDY) (13) and the Nurse Entry to Practice (NETP) program ${ }^{(14)}$ are available across Australia and New Zealand. Collectively, these are designed to transition new graduate nurses to practice

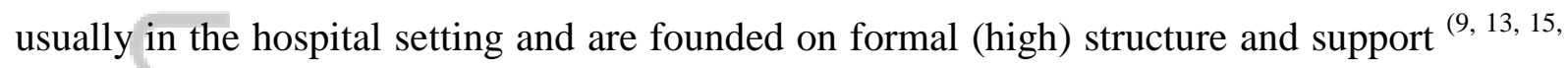
16). For example, the NETP program offered by employers generally comprises a learning framework, clinical rotations, preceptorship, study and development days and cultural support $(14,15)$

This article is protected by copyright. All rights reserved. 
The aim of this research is to describe the experiences of Australian and New Zealand nursing and midwifery students looking for employment after graduation.

\section{METHODS}

Our findings are drawn from a sub-study of the Graduate e-Cohort Study (GeS). The aim of the GeS was to examine employment choices by new graduates ${ }^{(17)}$.

Findings reported here are drawn from 2008, 2009 and 2010 Australian and New Zealand nursing and midwifery graduates and describe their experiences around gaining employment as a nurse or midwife. In effect, this means 2008 graduates were looking for work from 2009 onwards; graduates from 2009 were looking for work in 2010 onwards and so on.

\section{Design}

\section{Participant sample}

The sample $(n=197)$ comprised mostly female $(n=187)$, Registered Nurses $(n=185)$ who had graduated in $2008(n=64), 2009(n=93)$ and $2010(n=40)$. Respondents received their original degree in New Zealand (47\%) and Australia (53\%) and the majority $(n=176)$ were currently employed as a nurse or midwife. Table 1 contains sample characteristics for employment status (full-time; part-time), country of employment, employment organisation (public/private) and work setting. 
[Insert Table 1 here]

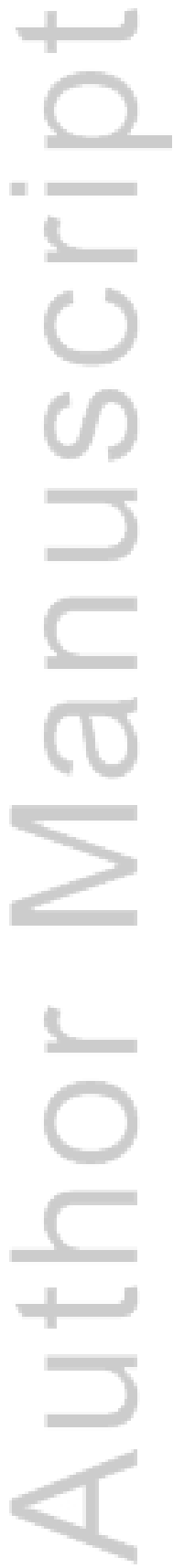

This article is protected by copyright. All rights reserved. 
Included in the GeS survey questionnaire was an open-ended prompt inviting respondents to "Describe your experiences gaining employment as a nurse or midwife after graduation”.

Of the $n=197$ respondents, $n=176(89 \%)$ provided complete demographic data. Respondent data were labelled with a unique number, their year of graduation and country of origin. For example, 472008A or $752008 \mathrm{NZ}$ indicated the respondents (47 or 75) were graduates of 2008 from Australia and New Zealand, respectively. The responses ranged from a few words to lengthy paragraphs; a sub-set of which provided the data for this article.

\section{Ethical considerations}

The Behavioural and Social Sciences Ethical Review Committee of The University of Queensland and the Massey University Human Ethics Committee approved the current study.

\section{Data analysis}

Content analysis was applied to written responses from the open-ended prompt ${ }^{(18)}$. The data were read and excerpts assigned descriptive labels amid looking for similarities and differences in what was shared by the respondents. Responses were then assigned to the broad categories: positive and negative experiences $(19,20)$. The data in each category was re-read using constant comparative analyses to more fully derive prevailing patterns and decide upon 
illustrative quotes ${ }^{(21)}$. Through conversations among the authors (AT, JO) consensus was reached about the patterns, and labels for the two inductively derived themes assigned: 1) Taking what you can get and 2) I already had a job lined up ${ }^{(22)}$. In further reviewing the coded data by year graduated, we found that graduates of 2008 (looking for jobs after graduation in the year 2009 and beyond) expressed fewer negative experiences than the 2010 and 2011 cohorts. In fact, graduates of 2009 and 2010 collectively described their experiences looking for and gaining employment as a nurse or midwife after graduation as challenging and impacting them psycho-emotionally. The analyses continued in the writing up of the findings and the current article.

\section{RESULTS}

\section{Taking what you can get}

Central to the theme 'taking what you can get' were the graduates' challenges around finding work in their preferred area of practice or securing permanent or ongoing employment. There were also delays for some graduates finding a job; and the threat of unemployment which then influenced considerations for relocating to secure work.

Nursing and midwifery graduates of 2008 looking for work described their experience as 'scary' (472008A), 'a hassle' (832008NZ), and 'difficult to get experience in an area that you want to work' (752008NZ). This difficulty in finding permanent work resonated with a 2008 midwife:

..After the grad year there is no chance of getting any permanent midwifery hours (372008A) 
Similarly, graduates of 2009 looking for work described their experience as 'nerve racking. Apprehensive' (962009A) and 'stressful due to the uncertainty' (942009A):

A challenge requiring me to be mobile across facilities and locations and clinical environments for instance the current hospital in which I work in the intensive care unit is the seventh hospital I have worked at (1282009A)

Encapsulating the Australian graduates of 2009 were the following:

Difficult gaining a graduate midwife position (1502009A)

Difficult to get grad positions at all, next to impossible to get one in an area of preference. Easier once out of grad timeframe (1522009A)

It was exceedingly difficult(1692009A)

This difficulty was borne out by a 2009 graduate who, facing unemployment, selffunded an additional course:

I ended up financing myself a phlebotomy course so I could try and earn some money in the industry.. finally, five months after finishing my university degree I had found some work in the field that I had dedicated so much time, sweat and tears to! (1692009A)

The data reveals an emphasis on this 'difficulty' by New Zealand graduates of 2009. Whilst it 'was initially quite hard but once I got a job it was ok...' (2562009NZ), the respondents generally noted:

(It was) difficult to get interviews and job offers (2372009NZ)

I found it difficult and was only offered one interview which resulted in a job offer (2752009NZ)

This article is protected by copyright. All rights reserved. 
Nursing and midwifery graduates of 2010 looking for work after graduation described their experiences: 'it was tough..' (2942010A), 'very difficult..' (2502010A) and just plain 'difficult!..' (2832010A). For some, finding work meant moving:

I had to move to the Gold Coast just to get the job I wanted (2942010A)

I moved from a capital city to a regional town to gain permanent employment (2502010A)

Similarly, finding work near home after completion of a graduation program (' grad.' year") impacted a 2008 graduate:

I have found it really difficult to find employment as a nurse as I live rurally and have two young children so finding anything close to home and family friendly (remains) proving impossible at this point in time (1352008NZ)

Again, the data revealed a strong emphasis on this 'difficulty' by New Zealand graduates of 2010. What participants experienced then was a lag time between applying for work and securing a job:

Very difficult, applied for a number of roles, didn't find employment until 4 months after graduation (4132010NZ)

It was incredibly difficult finding a job after graduation...They were not recruiting any new graduate nurses... 6 months after graduation I landed a fantastic job. (4512010NZ)

For graduates who were mobile and versatile, opportunities to find work increased and in this regard some respondents invested their energy in exploring job markets outside their locale and/or preference for clinical work. For some in New Zealand graduating in 2009, Australia was a more favourable employment prospect:

This article is protected by copyright. All rights reserved. 
Difficult getting opportunities in specialities I wanted to work in in NZ but not in Australia and conditions and income far better in Australia (2472009NZ)

Nursing and midwifery graduates of 2009 looking for work after graduation were also experiencing supply and demand pressures such that there were 'Many applicants, not many positions' (1992009NZ); 'Limited, only 4 graduate positions in my hospital which was not my first choice' (1332009A). This restrictive employment environment was exacerbated by a public - private health care dichotomy:

Did not get any offers of employment from public system (so took) employment in a graduate program at a private hospital (1702009A)

I also felt a great deal of competition ... as places in supported new graduate programmes [NETPS] were so limited .... I had heard that it would be easy to gain employment as a nurse; however most positions were seeking experienced nurses (1432009NZ)

Similarly, graduates of 2010 looking for work experienced a competitive job market where positions were limited, and being willing to move did not necessarily result in employment:

Made numerous applications and got one interview out of town but they gave the job to somebody who already lived there (3452010NZ)

Such was the volatility of job markets that some respondents were forced to consider alternatives to clinical practice. As a 2010 graduate suggested this could work out well:

Unable to get an interview for graduate program in a public hospital (or)...gain employment in area of interest. So went for a job with good hours and much better pay than a new grad.' position as a research nurse. Still in this area (3022020A) 


\section{I already had a job lined up}

Respondents included in the 'I already had a job lined up' theme provided a stark contrast to those who were force to take what they could get. For the graduates of 2008 and 2009 in particular, gaining employment was also buoyed by scholarships and offers of jobs during student clinical placement, most often from hospitals where they completed their final practicum. In contrast, few graduates of 2010 linked their clinical placement/practicum with post-graduation employment.

Generally, 2008 graduates from both Australia and New Zealand benefited from a clinical model with clinical practicum in the final year:

No problem. Had a position offered at pre-reg placement ...I considered myself very lucky as I had friends who found it much more difficult (1122008NZ)

After graduating I already had a job lined up with the unit I completed my pre-reg at. It was a very straight forward and I have since been able to get a job in the same specialty in the UK (952008NZ)

It was very easy as I initially applied for a position where I had completed my final prac[ticum] (772008A)

This exposure to a ward and organisation in the final year resulted in some 2008 graduates remaining attached to that workplace:

I am still at the same hospital I did my grad' year with (422008A)

Did my Nursing Prac' as an undergraduate in the ward I now work in as a CN [Clinical Nurse] (602008A) 
Nursing graduates of 2009 also benefited from being offered a job during the completion of their final year:

I was fortunate to get a job at the hospital where I did my practical part of the course. ..I only applied for that one job and got it!! (1032009A)

Was able to gain employment in my desired area prior to finishing my nursing degree, without any trouble (3092009NZ)

Got a new graduate placement at the hospital where I had done my placements as a student $(2462009 \mathrm{NZ})$

These opportunities were also available 'immediately upon completion of my midwifery degree at the hospital where I had done the majority of my clinical placement' (1532009A).

A few nursing and midwifery graduates of 2010 looking for work also described job offers from wards where they completed their final clinical practicum:

I was employed by the same company that I completed my 10-week final practicum (4212010NZ)

I had no problems finding work after graduation as I had made good connections with staff during placements and utilised these to find a job (4592010NZ)

Additionally apparent was the importance of the clinical placement as a conduit for employment where graduates were already known:

Offered a position before registration in the area where I had my final 10 week student placement. ... I was not offered a job for the other interview that I had in a different hospital (902009NZ)

I found it relatively easy to obtain employment after graduating, as I did my final clinical placement in the area I wanted to work in. However, I did apply for other 
areas also and was not even given an interview for areas I had not had a placement in (1432009NZ)

The graduates offered insights into the value (good and bad) of taking a job in an area where they had already worked. For one (good), the ward '(has) been very flexible and understanding with family situations' (1782009A). For another (bad), the opportunity was a segue to something better:

I was offered and took a job in the unit I had done my final prac in. It was horrible but I learnt a lot and was then able to get a job in an area I enjoyed more (1302009A)

Furthermore, unique to the data for nursing and midwifery graduates of 2008 was the reference to scholarship opportunities afforded to them whilst an undergraduate student:

I gained a QLD Health rural Scholarship while studying at [name of university] so was guaranteed employment in a rural hospital in QLD (302008A)

I received a scholarship while studying at [name of university] to receive my job at [name of hospital] (322008A)

Easy, job offer during clinical placement \& had rural/ remote nursing scholarship requiring bonded permanent full time employment/ placement for two years (402008A)

\section{DISCUSSION}

The findings drawn from the current study describe the experiences of Australian and New Zealand nursing and midwifery graduates from 2008, 2009 and 2010 looking for employment. We propose that the unique contribution of this research is that it addresses what Rumsfeld called the 'known knowns' (the things we know we know) and also offers insights about the 'known unkowns' (those things we know we do not know) about new nursing and 
midwifery graduates looking for employment ${ }^{(23)}$. Revealed are challenges around 'taking what you can get' wherein economic uncertainties simultaneously limited work options and supply amid heightening the anxieties of newly credentialed nurses who were looking for work. Public health and government supplemented higher education herein emerge as vulnerable but strategic in their fiscally driven human resource decisions and the willingness to educate ever expanding quotas of nurses and midwives. Of course, within this context new graduates can, and clearly are challenged by needing to pay their tuition debt and consolidate what they have learnt toward independent practice. The end result is that some graduates 'fail to launch' while others have limited tenure becoming victims of a system challenged by economic restraints and focussed on the bottom line.

Complicating this scenario nurses and midwives are needed, and a nursing shortfall remains on the horizon ${ }^{(24)}$. The nursing workforce is also aging ${ }^{(24)}$. If we are to have a sustainable healthcare workforce comprising nurses and midwives, we need to know about how to better facilitate and actively enhance the transition of the new nurse/midwife graduate to healthcare ${ }^{(25-27)}$. At a broader socioeconomic level, 'workforce participation can also contribute to social inclusion and equity benefits and help reduce costs associated with the providing welfare support for those not in the workforce' (28).

In terms of time and place the current study findings were similar across the three groups, although the graduates of 2009 and 2010 were especially challenged as were those from New Zealand. Concurring with previous research, findings here confirm the transition to the nursing workplace as potentially a hassle, nerve racking, stressful, uncertain and tough ${ }^{(1)}$. These adjectives cut across all three graduating years and New Zealand and Australia. 
Graduates, especially 2008 and 2009 nurses and midwives, struggled to find permanent positions. In pursuit of work, some moved hospitals to keep their employment viable (2009) or more crucially, moved away from their home town to find work $(2008,2010)^{(29,30)}$. By comparison to the 2008 graduates, the emphasis and depth of the qualitative data for nurses and midwives of 2009 and 2010 revealed they found it hard to secure job interviews and were confronted with a perceived lack of positions. Where jobs were found, for both Australian and especially New Zealand graduates, a lag time existed between them graduating and getting employment; for some up to six (6) months. Additionally, consistent with the economic market at the time, New Zealand graduate nurses and midwives looked to the Australian labour market as more favourable and set offshore looking for work ${ }^{(31)}$.

For respondents included in the theme, I already had a job lined up, most nurse/midwife graduates reported securing a job in the organisation where their final undergraduate year clinical practicum was taken ${ }^{(32)}$. This was universal across the three groups, although the data suggested these opportunities were fewer for graduates of 2010 . A number of contextual elements inform our discussion of the job/clinical practicum binary, as an issue experienced by Australian and New Zealand new nursing and midwifery graduates. Undoubtedly, securing a scholarship is an attractive option and can be leveraged to ensure employment options into the future. It may be the case here that the graduates of 2008 were in a unique situation. Nevertheless, we would support the scholarship option particularly to entice new graduates into the healthcare workforce where there is potential staffing shortfalls, such as mental health and aged care (specialty) and in rural, remote and outer metropolitan regions (geographical) ${ }^{(24)}$. 
Furthermore, the importance of securing a job in the organisation where a final year undergraduate clinical practicum was taken, is underscored by those graduates who were unable to secure an interview and/or job offer within hospitals where they were not known. Additionally, the data provides a caveat. Whilst the clinical placement period, particularly in the final year, can give undergraduate nursing/midwifery students an opportunity to evaluate their match with a potential ward a 'took what I could get' resolve might also prematurely influence graduates to take a less than ideal 'fit'. Employers need to be reminded of the importance of providing a graduate nurse/midwife with a supportive clinical experience with their organisation ${ }^{(19)}$. Graduate nurses with prior supportive clinical experience with an organisation, may prize less the extrinsic work values like salary, instead triaging intrinsic work benefits including promotion and the opportunity to refine and develop new skills $(33,34)$

The findings also have implications for universities. In particular, there is likely significant benefits to more actively coaching students about networking and the importance of preforming consistently well in student clinical placements ${ }^{(35-37)}$. Notwithstanding the connectedness between economies and challenges for securing work as a nurse or midwife, the current findings suggest that strategic efforts to leverage toward paid employment should occur throughout the program rather than at the end of the program. For graduates, especially those who will inevitably experience challenges with the transition to full time work, an honours program might also be especially helpful in developing skillsets to increase the range of nursing jobs to which they might competitively apply ${ }^{(38,39)}$.

Nurses are characterized as a mobile workforce, and economic uncertainty can serve to drive such patterns ${ }^{(40,41)}$. With this in mind there may be some benefit to signalling early on 
in the student recruitment process that graduate year programs may require moving interstate and/or relocation to rural or remote locales. Related to this, encouraging students to explore all their graduate program options would likely reduce the challenges finding work by reducing demand in larger institutions.

The current study findings have implications for an array of threats and opportunities in regards to nursing practice and research. In terms of threats, the major concern is that baccalaureate prepared registered nurses and midwives experience challenges finding employment to the extent that they take up jobs or subsequent education options outside of nursing. Challenges around securing work within preferred clinical areas also inform vulnerabilities around retention, wherein we know that long-term workplace dissatisfaction leads to resignations and/or burn out ${ }^{(42-45)}$. Of course, the threats here extend beyond nurses themselves and have implications for the quality of patient care and the direct costs associated with replacing beginning nurses amid the absence of experienced independent nurses. In terms of remedy, it is clear that both universities and health care providers have important opportunities to make a difference to the beginnings, and ultimately the trajectories of newly graduated nurses and midwives. For example, universities by including coaching around the connections between performing consistently well on clinical and strategies for being known to potential employers could go some way to preparing graduates for the job market ${ }^{(35,36)}$. In addition, the hiatus in full time work options for graduates might be buffered by universities offering part time programs to assist the student to develop clinical teaching, leadership and research skills $^{(46,47)}$. Such initiatives would assist graduates to more fully explore all their nursing preferences and options. Clinical settings might also have opportunities to formally 
evaluate the reasons why nurses are lost to their respective organizations by way of analysing and reporting the findings drawn from exit interviews. This 'needs analysis' could reveal much toward developing targeted workplace health promotion programs and/or adjustments to recruitment and retention strategies, formally evaluated to learn from innovation around developing nurses to realize their full collective potential ${ }^{(48,49)}$.

A number of study limitations need to be noted. Even with a sizeable sample $(n=176)$ the one-off snapshot or cross-sectional study design is limited by our inability for follow-up clarification or additional complementary data. Nor might the sample be representative of all graduates in Australia and New Zealand, and participants are geographically confined to these countries, which limits global transferability of findings ${ }^{(22)}$. Whilst qualitative data is also limited in terms of transferability (external validity), this limitation provides direction for future research. For example, a longitudinal research design could garner formal comparisons across time (i.e., 2011, 2012, 2103 etc) and place (Australia, New Zealand, Canada) to distil patterns, diversity and changes toward forecasting the trajectories, and addressing the challenges likely facing future nursing and midwifery graduates.

\section{CONCLUSION}

The findings drawn from the current research offer educators, policy makers and administrators alike insights toward supporting the transitions of newly graduated nurses and midwives. We revealed characteristics common to the transition experiences amid highlighting the importance of the final clinical placement in securing employment after 
graduation. We also proposed strategies to better facilitate and actively enhance the transition of new nurse/midwife graduates into the healthcare workforce.

\section{Acknowledgements}

We acknowledge and thank all the graduate nurses who participated in this sub-study and who continue to participate in and support the Graduate eCohort Study.

\section{Disclosure}

The authors declare no conflict of interest

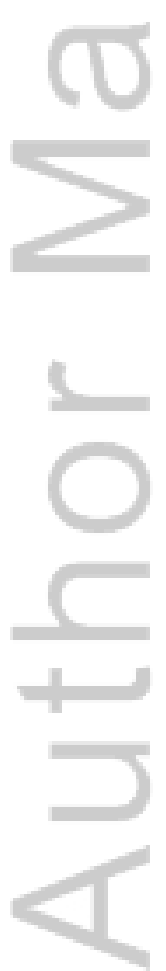

This article is protected by copyright. All rights reserved. 


\section{REFERENCES}

1. Boychuk Duchscher J. Transition shock: the initial stage of role adaption for newly graduated Registered Nurses. Journal of Advanced Nursing. 2009;65(5):1103-13.

2. Tastan S, Unver V, Hatipoglu S. An analysis of the factors affecting the transition period to professional roles for newly grdauated nurses in Turkey. International Nursing Review. 2013;60:40512.

3. Hayman_White K, Happell B, Charleston R, Ryan R. Transition to mental health nursing through specilaist graduate nurse programs in mental health: A review of the literature. Issues in mental health nursing. 2007;28:185-200.

4. = Thomas C, Bertram E, Allen R. The transition from student to new Registered Nurse in professional practice. Journal for Nurses in Staff Development. 2012;28(5):243-9.

5. Cleary M, Horsfall J, Muthulakshmi P, Happell B, Hunt G. Career development: graduate nurse views. Journal of Clinical Practice. 2013;22:2605-12.

6. Australian Institute of Health and Welfare. Australia's Health 2010: AIHW; 2010 [cited 2016

12th February]. Available from: http://www.aihw.gov.au/publication-detail/?id=6442468376.

7. Cowin L, Hengstberger-Sims C. New graduate nurse self-concept and retention: A longitudinal survey. International Journal of Nursing Studies. 2006;43:59-70.

8. Australian Institute of Health and Welfare. How many nurses and midwives are there? : AIHW; 2014 [cited 2016 12th February]. Available from: http://www.aihw.gov.au/workforce/nursingand-midwifery/how-many/.

9. Halfer D, Grafe E, Sullivan C. The organisational impact of a new graduate pediatric nurse mentoring program Nursing Economics. 2008;26(4):243-9.

10. Skancke Bjerknes M, Torrun Bjork I. Entry into nursing: An ethnographic study of newly qualified nurses taking on the nursing role in a hospital setting. Nursing Research and Practice [Internet]. 2012.

11. Harrison T, Stewart S, Ball K, Meyer Bratt M. Clinical focus program: Enhancing the transition of senior nursing students to independent practice. Journal of Nursing Administration. 2007;37(6):311-7.

12. Morphet J, Considine J, McKenna L. Transition to specialty practice programs in emergency nursing- A review of the literature. Australasian Emergency Nursing Journal. 2011;14:45-9.

13. Morphet J, McKenna L, Considine J. The career development year: Responding to the emergency nursing shortage. Australasian Emergency Nursing Journal. 2008;11:32-8.

14. Haggerty C, McEldowney R, Wilson D, Holloway K. Growing our own: An evaluation of Nurse Entry to Practice Programmes in New Zealand 2006-2009. Wellington: Ministry of Health, 2009.

15. Missen K, McKenna L, Beauchamp A. Graduate nurse program coordinators' perspectives on graduate nurse programs in Victoria, Australia: A descriptive qualitative approach. Collegian. 2016;23(2):201-8.

16. Haggerty C, Holloway K, Wilson D. Entry to nursing practice preceptor education and support: Could we do it better? Nursing Praxis in New Zealand. 2012;28(1):30-9.

17. Huntington A, Gilmour J, Neville S, Kellett S, Turner C. A glimpse of the future nursing workforce: The Graduate e-cohort study Australian Journal of Advanced Nursing [Internet]. 201213 February 2016; 29(3):[22-9 pp.]. Available from: http://search.informit.com.au.ezproxy.library.uq.edu.au/documentSummary;dn=265024992410389;res =IELAPA. 
18. Morgan D. Qualitative content analysis: A guide to paths not taken. Qualitative Health Research. 1993;3:112-21.

19. Tuckett A, Winters-Chang P, Bogossian F, Wood M. 'Why nurses are leaving the profession...lack of support from managers': What nurses from an e-cogort study said. International Journal of Nursing Practice. 2015;21:359-66.

20. Tuckett A, Hughes K, Gilmour J, Hegney D, Huntington A, Turner C. Caring in residential agedcare. Qualitative findings from an e-cohort sub-stuy. Journal of Clinical Nursing. 2009;18:260412.

21. Charmaz K. 'Discovering' chronic illness:using grounded theory. Social Science and Medicine. 1990;30:1161-72.

22. Tuckett A, Turner C. Do you use social media? A study into new nursing and midwifery graduates' uptake of social media. International Journal of Nursing Practice [Internet]. 2015 13th February 2016. Available from: http://onlinelibrary.wiley.com/doi/10.1111/ijn.12411/epdf.

23. Rumsfeld D. DoD News Briefing2002 06/06/2016. Available from: http://archive.defense.gov/Transcripts/Transcript.aspx?TranscriptID=2636

24. Health Workforce Australia. Health Workforce 2025: Consumer Edition. Adelaide, South Australia: HWA, 2014.

25. Gray M, Clark M, Penman M, Smith J, Bell J, Thomas Y, et al. New graduate occupational therapists feelings of preparedness for practice in Australia and Aotearoa/New Zealand. Australian Occupational Therapy Journal. 2012;59:445-55.

26. Lea J, Cruickshank M. The support needs of new graduate nurses making the transition to rural nursing practice in Australia. Journal of Clinical Nursing. 2014;24:948-60.

27. Morrow S. New graduate transitions: leaving the nest, joining the flight. Journal of Nursing Management. 2009;17:278-87.

28. Department of Education Employment and Workplace Relations. Australian labour market update July 2011. Australia: DEEWR, 2011c.

29. Corcoran J, Faggian A, McCanin P. Human Capital in Remote and Rural Australia: The Role of Graduate Migration. Growth and Change. 2010;41(2):192-220.

30. Hawthorne L, To A. Australian Employer Response to the Study-Migration Pathway: The Quantitative Evidence 2007-2011. International Migration. 2014;52(3):99-115.

31. Department of Labour. Labour market update December 2011. New Zealand: Department of Labour (DoL), 2011b.

32. Johnson G, Blinkhorn A. The influence of a clinical rural placement programme on the work location of new dental graduates from the University of Sydney, NSW, Australia. European Journal of Dental Education. 2013;17:229-35.

33. Duncan K. Student pre-entry experience and first year of employment. The Journal of Continuing Education in Nursing. 1997;28(5):223-30.

34. Tuckett A, Parker D, Eley R, Hegney D. 'I love nursing, but..'- qualitative findings from Australian aged-care nurses about their intrinsic, extrinsic and social work values. International Journal of Older People Nursing. 2009;4(4):307-17.

35. Jones R, Woods S, Guillaume Y. The effectiveness of workplace coaching:A meta-analysis of learning and performance outcomes from coaching. Journal of Occupational and Organizational Psychology [Internet]. 2015 13th February 2016:[1-29 pp.]. Available from: http://onlinelibrary.wiley.com/doi/10.1111/joop.12119/epdf.

36. Rafferty R, Fairbrother G. Factors influencing how senior nurses and midwives acquire and integrate coaching skills into routine practice: a grounded theory study. Journal of Advanced Nursing. 2015;71(6):1249-59. 
37. Chichester M. Making Connections to Develop a Professional Network. Nursing for Womens' Health. 2014;18(2):163-7.

38. Bull R, Shearer T, Phillips M, Fallon A. Supporting Graduate Nurse Transition: Collaboration Between Practice and University. The Journal of Continuing Education in Nursing. 2015;46(9):40915.

39. Hawes C, Scmidzt K. A model for the future. Integration of the Bachelor of Nursing honours degree with the graduate nurse program. Collegian. 2000;7(2):10-3.

40. Eley R, Buikstra E, Plank A, Hegney D, Parker V. Tenure, mobility and retention of nurses in Queensland, Australia: 2001 and 2004. Journal of Nursing Management. 2007;15:285-93.

41. Cutcliffe R, Bajkay R, Forster S, Small R, Travale R. Nurse Migration in an Increasingly Interconnected World: The Case for Internationalization of Regulation of Nurses and Nursing Regulatory Bodies. Archives of Psychiatric Nursing. 2011;25(5):320-8.

42. Coomber B, Barriball K. Impact of job satisfaction components on intent to leave and turnover for hospital-based nurses: A review of the research literature. International Journal of Nursing Studies. 2007;44:297-314.

43. Hayes L, O'Brien-Pallas L, Duffield C, Shamian J, Buchan J, Hughes F, et al. Nurse turnover: A literature review - An update. International Journal of Nursing Studies. 2012;49:887-905.

44. Warshawsky N, Havens D. Nurse Manager Job Satisfaction And Intent to Leave. Nursing Economics. 2014;31(1):32-9.

45. Zhou W, He G, Wang H, He Y, Yuan Q, Liu D. Job dissatisfaction and burnout of nurses in Hunan, China: A cross-sectional survey. Nursing and Health Sciences. 2015;17:444-50.

46. Blackstock S, Exner N. Student nurses conducting research amongst their peers: Lessons learned. ABNF Journal. 2012;23(4):94-6.

47. Morris D, Turnbull P. Using student nurses as teachers in inquiry-based learning. Journal of Advanced Nursing. 2004;45(2):136-44.

48. Glossop C. Student nurse attrition: use of an exit-interview procedure to determine students' leaving reasons. Nurse Education in Practice.22:375-86.

49. Webster J, Flint A. Exit interviews to reduce turnover amongst healthcare professionals (Review). Cochrane Database of Systematic Reviews. 2014(8):Art. No.: CD006620. 
Table 1: Characteristics of participants $(n=197)$

\begin{tabular}{|c|c|c|}
\hline \multirow[t]{2}{*}{ Characteristic } & \multicolumn{2}{|c|}{ Total } \\
\hline & $\mathbf{n}$ & $\%$ \\
\hline \multicolumn{3}{|l|}{ Gender } \\
\hline female & 187 & 95 \\
\hline male & 10 & 5 \\
\hline \multicolumn{3}{|l|}{ Designation } \\
\hline Registered Nurse (RN) & 185 & 94 \\
\hline Registered Midwife (RMW) & 20 & 10 \\
\hline Registered Nurse + Midwife & 8 & 4 \\
\hline \multicolumn{3}{|l|}{ Year of Graduation } \\
\hline 2008 & 64 & 33 \\
\hline 2009 & 93 & 47 \\
\hline 2010 & 40 & 20 \\
\hline \multicolumn{3}{|l|}{ Country of original undergraduate degree } \\
\hline Australia & 104 & 53 \\
\hline New Zealand & 93 & 47 \\
\hline \multicolumn{3}{|l|}{ Currently employed as Nurse/Midwife } \\
\hline Yes & 176 & 89 \\
\hline No & 21 & 11 \\
\hline \multicolumn{3}{|l|}{ Employment Status $^{\S}$} \\
\hline Fulltime/Permanent & 93 & 53 \\
\hline Fulltime/Temporary & 7 & 4 \\
\hline Part-time Permanent & 60 & 34 \\
\hline Part-time/Temporary & 4 & 2 \\
\hline Casual & 12 & 7 \\
\hline \multicolumn{3}{|l|}{ Country Employed $^{\S}$} \\
\hline Australia & 105 & 60 \\
\hline New Zealand & 65 & 37 \\
\hline Great Britain & 2 & 1 \\
\hline Other & 4 & 2 \\
\hline \multicolumn{3}{|l|}{ Employment Organisation $^{\S}$} \\
\hline Public & 134 & 76 \\
\hline Private & 42 & 24 \\
\hline \multicolumn{3}{|l|}{ Work Setting $^{\S}$} \\
\hline Acute Hospital & 124 & 71 \\
\hline $\begin{array}{l}\text { Aged Care, Prison, Hospice, Defence } \\
\text { Force Education, Government } \\
\text { Department, Outpatient Clinic, } \\
\text { Domiciliary/Community }\end{array}$ & 12 & 7 \\
\hline School Setting & 10 & 6 \\
\hline Maternity/Birth Centre & 8 & 5 \\
\hline
\end{tabular}




\begin{tabular}{|l|l|l|}
\hline Medical Practice & 7 & 4 \\
\hline Community Health Centre & 6 & 3 \\
\hline Integrated Hospital/Clinic/Community & 4 & 2 \\
\hline Day Surgery & 3 & 2 \\
\hline Independent Practice & 2 & 1 \\
\hline
\end{tabular}

$\S$ Total of 21 respondents did not provide this information.

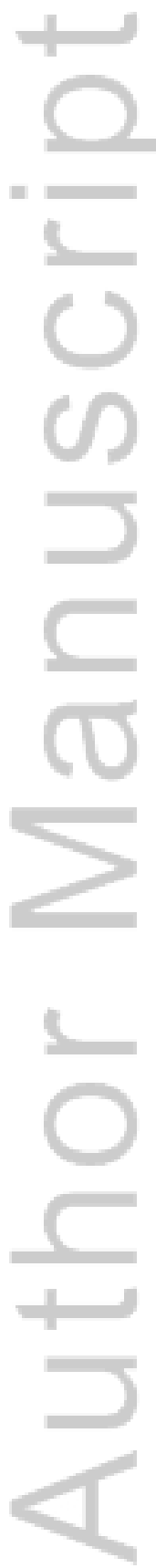

This article is protected by copyright. All rights reserved. 


\section{University Library}

\section{- M M N E R VA A gateway to Melbourne's research publications}

Minerva Access is the Institutional Repository of The University of Melbourne

Author/s:

Tuckett, A;Oliffe, JL

Title:

Experiences of Australian and New Zealand new nursing and midwifery graduates looking for employment

Date:

2016-12-01

\section{Citation:}

Tuckett, A. \& Oliffe, J. L. (2016). Experiences of Australian and New Zealand new nursing and midwifery graduates looking for employment. INTERNATIONAL JOURNAL OF NURSING PRACTICE, 22 (6), pp.616-624. https://doi.org/10.1111/ijn.12484.

Persistent Link:

http://hdl.handle.net/11343/291842 